\title{
Classical Cases Study on the Construction of City Subsidiary-Centers in Japan
}

\author{
Zhao Fang, Liu Yanjun, Zhang Wei, Wu Qiong, Hu Linyue \\ Beijing Institute of Science and Technology \\ Beijing, China \\ Email:zfmm823@163.com
}

\begin{abstract}
In the context of the rise of urban sub centers in China's major cities, to offer counselling service, the latest information and data of typical urban sub centers in Japan has been collected through information tracking by professionals. Compared with gathering information of a single case, this is a comprehensive information collection which has never been executed. All Japan's City Subsidiary-Centers are divided into comprehensive and functional type, and the latter type is further divided into administrative dominated and business office types. According to this classification, this paper introduces the sub centers, such as the geographical position, land planning and use, industrial distribution, institutions, and population. On this basis, it also sums up the general and the characteristic management experience of these urban sub centers in Japan.
\end{abstract}

Keyword-urban sub center; land planning; population; transportation hub; industry

\section{INTRODUCTION}

The ongoing discussion of Tongzhou "How to assume Beijing's future development" as a sub-center of Beijing has caused wide concern. In fact, in addition to Beijing, Shanghai, Guangzhou, Shenzhen, Tianjin, Chongqing, Zhengzhou, Hefei, Hangzhou and many other cities all are planning and building their own city sub centers. City subsidiary-center construction is a far-reaching and complex project. By referring to the existing experiences and lessons, we can reduce risks of "wading across the river by groping for stones". Japan has a lot of city subsidiary-centers and each is with distinctive characteristics which can be of great value for references. By summing up the status quo of various city subsidiary-centers of Japan based on the existing data and Japan official statistics, the paper provides a macro-overview of the city subsidiary-centers in Japan as well as information clues for the in-depth and detailed study.

\section{TYPES OF CITY SUBSIDIARY-CENTERS}

According to the functional classification, Japan's city subsidiary-centers are divided into comprehensive and functional types. And the former includes Ikebukuro, Tokyo, Osaka Business Park; the latter is further divided into administrative dominated and business office types with Saitama Tokyo for the former and Shinjuku Tokyo, Makuhari, Yokohama MM21 for the latter.

To be specific, the functional type can be divided into 8 types of administrative dominated center, financial dominated center, business office center, cultural tourism, centers for convention and exhibition, centers for science and technology, international trade centers, and retail business centers. In some function-oriented types, cases in Japan are not introduced, but it does not mean that Japan's city subsidiary-centers have no those functions. Comparatively speaking, they are not so characteristics or are slightly inferior to those in other countries in this respect.

\section{OVERVIEW OF JAPAN’S CITY SUBSIDIARY-CENTERS}

\section{A. Comprehensive urban sub-centers}

1) Ikebukuro, Tokyo: In 1958, Tokyo Development Committee decided to build Ikebukuro as one of the sub centers of Tokyo. The area now has developed into a famous integrated city sub-center of Tokyo, combining business, culture, education and transportation.

Taking the Ikebukuro Station as center and dividing line, Ikebukuro is divided into West and East Exist Areas. Along the street from the east of Ikebukuro Station to the Sunshine City, there stand numerous large department stores, appliance stores, boutiques, cinemas, restaurants, recreation centers, large convention centers with exhibition halls. The West Exist Areas is built with the cultural facilities such as Tokyo Metropolitan Theatre, Metropolitan Hotel, and Rikkyo University and so on, radiating strong sense of culture, forming a different atmosphere from the East Exit area.

As a transportation hub, railway lines including Yamanote Line, Saikyo Lin, Tokyo Metro Fukutoshin Line, Seibu Ikebukuro Line all have stations in Ikebukuro Station; subway Yurakucho Line stations at Higashi-Ikebukuro Station; streetcar stops at Higashi-Ikebukuro-yonchōme Station ;capital high-speed Line 5 Ikebukuro Lineruns through this area . Ikebukuro Station is the busiest station second only to Shinjuku Station in Japan and also the world's busiest railway station second only to Shinjuku Station. As a commercial center, the region gathers manufacturing, wholesale, retail, construction, service industries and other small, medium and large enterprises, providing job opportunities for great many people. In terms of culture and education, the area has complete education system from kindergartens to universities, including public and private schools. Among which, there are Gakushuin University, Tokyo College of Music, Rikkyo University, and Taisho University. In addition, there are also well-known arts theatre and exhibition hall in the area.

Population explosion is the severe "great urban disease" of Tokyo. After the completion of Ikebukuro, its population 
carrying capacity is considerably high. Ikebukuro is located in Toshima-Ku of Tokyo. According to the 2010 census result, Toshima-Ku ranked the first population density as a self-governing body in Japan. Based on the July 12, 2016 statistics on Toshima-Ku official website, the total number of residents in Toshima- $\mathrm{Ku}$ is more than 280,000, with 25,000 foreigners. The population of Ikebukuro area (including Upper Ikebukuro, South Ikebukuro, Seibu Ikebukuro, Higashi-Ikebukuro, Ikebukuro, Ikebukuro town) takes up 35\% of the total number of Toshima-Ku. ${ }^{[1]}$

2)Osaka Business Park: Osaka Business Park (hereinafter referred to as OBP) is located in Osaka central area, made up of high-rise building groups and urban park redevelopment area, covering an area of 26 hectares. OBP is divided into five super blocks, with the largest area of 5.6 hectares and the smallest 1.3 hectares.

According to the plan, OBP, as the information, international, and cultural new base in Osaka along with many other features is aiming at built a 21 st century city with activities around the clock. The 21 st Century Twin Towers in the district is one of the biggest information buildings in Japan. Central Theatre is also the core facility for the cultural and information activities of OBP. International Telephone and Telegraph Corporation Shareholding Building is an important communications center in Japan. The hotels, luxury shops, clubs, hospitals in the neighborhood of Sumitomo Life Insurance Company Building provide a facility basis for OBP to achieve the goal of sleepless city. Based on the night population density statistics in 2010 , there were approximately 5,000 to 10,000 people in $1 \mathrm{~km}^{2}$ in the region, not the most active region, but degree of activity was also above average. (See Fig. $2^{[2]}$ )

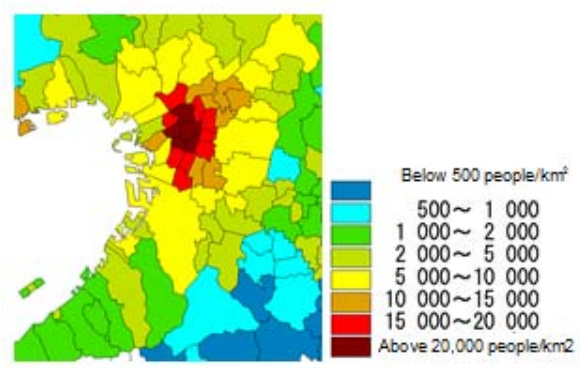

Fig. 1 Population density in Osaka districts (unit: person $/ \mathrm{km}^{2}$ )

As a CBD, according to the 2014 statistics of Japan Statistics Bureau, the organizations / institutions / companies in the range of $1 \mathrm{~km}^{2}$ exceeded 500 (see Fig. 2A), it was one of the areas in Japan with the highest density of organizations / institutions / companies. In the same year, the number of people employed in $1 \mathrm{~km}^{2}$ was over 10,000 (see Fig. 2B). OBP area was also one of the places with the highest employment Fig..

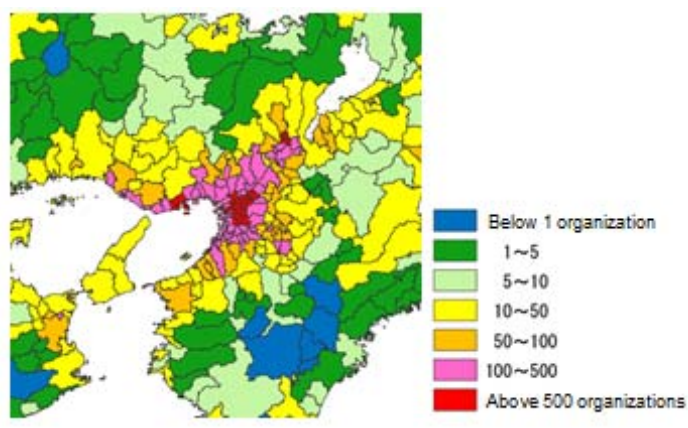

Fig. 2A Density of Japanese organizations / institutions / companies (unit: $/ \mathrm{km}^{2}$ )

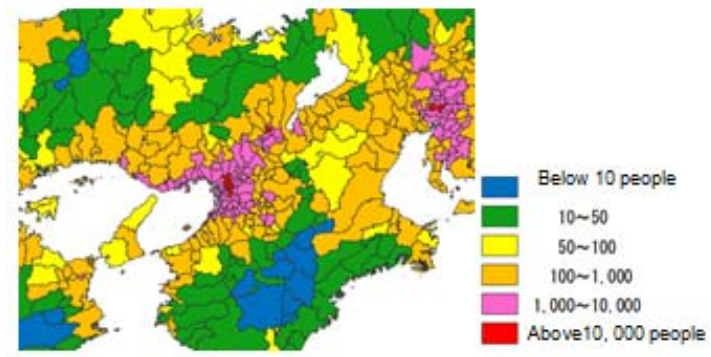

Fig. 2B Employment population density in Japan (unit: person $/ \mathrm{km}^{2}$ )

As a traffic stop center, it is the intersection of water buses, municipal subways, Japan railways, and Osaka ring roads. The top floor of the building has cast away the business operation and opened an motor vehicle access to the road at the west side where the motor vehicles can access the top traffic floor and go to a multi-story car park or an underground car park. Near the parking lot, vertical transportation such as escalators and lifts are installed to facilitate the people in the traffic floor to reach other floors. The area linking the top floor and the road is designed into the passing access for motor vehicles. The traffic floor linking to the underground traffic rails is also facilitated with the escalator to the second floor.

\section{B. Administrative dominated type}

1) Saitama sub-center, Tokyo: Not to over-concentrate the economy and administration in Tokyo, the Japanese government has made renovation to the former site of Omiya Station and developed into Saitama New Urban Center, assuming some of the capital functions of Tokyo.

Saitama New Urban Center is built with national comprehensive office buildings stationed by government authorities (central government offices) and Kanto local authorities (provincial offices and local authority divisions), which currently include: Ministry of Justice, Ministry of Health, Labour and Welfare, Ministry of Finance, National Police Agency of Japan, Ministry of Defence, Ministry of Internal Affairs and Communications, Ministry of Agriculture, Forestry and Fisheries, Ministry of Economy, Trade and Industry, Ministry of Land, Infrastructure, Transport and Tourism, Ministry of the Environment, and National Personnel Authority. By sharing the administrative functions of Tokyo as the capital, Saitama has virtually become a New Urban Center. Saitama New Urban Center is the largest business district in Saitama Prefecture where it is built with tall civil buildings, Saitama Super Arena, Besshonuma Park, Shintoshin Cocoon, 
John Lennon Museum, as well as many office buildings. In addition, the infrastructure also includes Saitama New Urban Transit, sidewalks above the ground of two floors connecting with all facilities, urban planning roads, district streets, Metropolitan Expressway, utility lines, storm water detention basins, etc. As of July 2016, the total population of Saitama New Urban Center region (Central and Omiya areas) is reported to have 214,806 people. ${ }^{[3]}$

\section{Business office type}

1) Shinjuku, Tokyo: Shinjuku is one of the 23 special wards of Tokyo, covering an area of 18.23 square kilometers. Located in the central west area, close to the old CBD (Chiyoda, Minato, Central District), it is one of the main downtown areas of Tokyo. Taking JR Shinjuku Station at the center, Shinjuku sub-center consists of three functional areas. Higashi Shinjuku is the traditional CBD, consisting of famous product street and the Kabuki Street of entertainment. Nishi-Shinjuku is the administrative and commercial new urban center, and home to banking, securities trading, information, media, and other large company headquarters, offices, government agencies, and high-end restaurants and others. South Shinjuku is a multifunctional area with information industry, offices and shopping centers, etc.

Shinjuku sub-center mainly serves for business functions. The built CBD covers 16.4 hectares, accounting for $90 \%$ of the total area of Shinjuku. Among which, the building area for commercial and office buildings takes up more than 3 million square meters housing over 40 super high-rise buildings. From 1980 to 2014, Shinjuku's employment rate in the first and second industries decreased and the third industry employment proportion was on the rise. In 2014, the CBD became a center for economic, administrative, commercial, and cultural and information sectors; the employment mainly concentrated in wholesale and retail industry $(15 \%)$, medical security industry $(10 \%)$, information communications industry $(9.8 \%)$, catering and accommodation (9.6\%), academic research and specifically technology services $(8.4 \%)$ and science \& technology industry $(8.3 \%)$; the structure of employment population is basically close to that of the central three districts, largely reducing the stress of the old CBD, Tokyo. The role of the financial industry is particularly obvious. Taking Shinjuku Station as the center, within a radius of 7, 000 meters only, it is crowded with more than 160 banks. Shinjuku has become the miniature of Japanese "bank war". ${ }^{[4]}$

The population in Shinjuku in 2010 reached 328,100, ranking the 12th among the districts of Tokyo; the population density ranked seventh; foreign population marked 25,700, first among the districts; the population at daytime was 750,000 and the permanent resident population at night was up to 326,000 people. From the perspective of population movements, the difference of Shinjuku and Chiyoda, the Central and Minato was $-22,000$ people, which indicated that Shinjuku had eased the stress of the old CBD of Tokyo.

2) Makuhari Sub-Center: Makuhari Sub-Center, located in Chiba Prefecture on the northeast shore of Tokyo Bay, between downtown Tokyo and Narita International Airport, covers a total area of 522 hectares. 84.6 hectares of which is for business office buildings, 33 hectares for commercial land,
38.9 hectares for residential land and 87.4 hectares for education. Among which, the business and commercial land is mainly around core stations of the high speed railways.

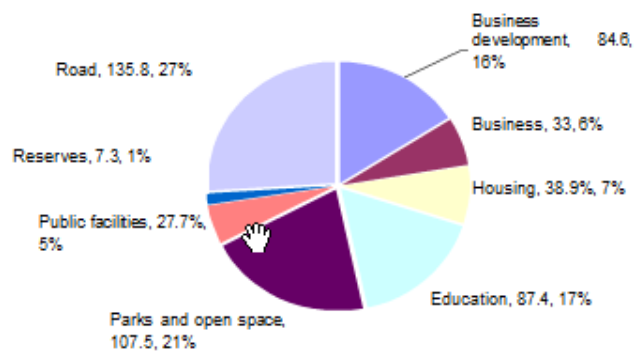

Fig. 3 Land planning proportion of Makuhari New Urban Center

Centered on Makuhari Messe, it brings the international business capabilities as well as the cutting-edge industrial administration, R\&D functions and educational functions together, and strives to realize comfortable, desirable living environment to meet the housing needs of future employment as well as the surrounding population. At present, Makuhari has become the location of the headquarters and R\&D bases of Japan domestic as well as international companies. Between 1989 and 1994 only, more than 15 Japanese and international enterprises have set up office bases in Makuhari. In addition, the adequate and good office environment has attracted more than 300 small and medium sized companies. The enterprises in this area primarily engage in international business management and R\&D activities. ${ }^{[5]}$

3) Yokohama MM21: As an important part of Tokyo metropolitan area, due to the very close distance with Tokyo, over time, Yokohama as the principal city's independence is gradually shrinking, and to some extent, it has developed into Tokyo's "sub-capital". Notwithstanding the Hommachi financial district and Yokohama Chinatown and other traditional CBDs, they are all old and do not match with the status of Yokohama as an international port city. In order to revitalize Yokohama and build a sub-center of independent business functions to ease the great pressure of Tokyo Business Office, and to enhance its own economic centrality, in 1982, the government established Yokohama MM21 development scheme.

MM21 is close to the former city center in the southwest and northeastern coast, facing the Bay Bridge, with "Minato Mirai Line", "International Chase" two trunks running through, superior in location and magnificent in landscape. The total land use is about 186 hectares, including the utilization of 110 hectares of the former old dock and warehouse areas; 76 hectares of land is reclaimed by filling the sea. The planned land use for business and residential area is 87 hectares, 46 hectares for park and greening, 11 hectares for terminal operations ( 42 hectares for roads and rails).

MM21 is mainly composed of: (1) commercial facilities, theatres, theme parks. For example: Yokohama Landmark Tower, Queen's Square Yokohama, TOC, Nippon Maru Memorial Park and so on. (2) Offices, business-related facilities. For example, headquarters of Nissan Motor Corporation, Mitsubishi Heavy Industries Yokohama Building, 
The Bank of Yokohama Head Office Building, Japan Oil and Gas Yokohama Building and so on. (3) Research and development facilities and institutions. For example: Fuji Xerox Research and Development Plaza, Lenovo Group (for Japanese) laptop research and development base, and so on. (4) Research, training facilities and institutions. For example: MUFG Global Education Center (Research and Training Institution of Mitsubishi UFJ Financial Group). (5) Hotels. (6) Parks, green spaces, sidewalks.

MM21, with the integration of enterprises, cultural facilities, research institutions, has provided the workplace and employment for the citizens, activated the local economy, established the regional economic foundation, thus has strengthened Yokohama's independence; by building parks, themed park, and green spaces, it has provided the public relaxation and sightseeing spaces; the city has also collected and expanded commercial and international exchange and other functions to share the related capital functions of Tokyo. In 2015, the tourists visiting MM21 reached about 76 million people, the number of the employment was about 102,000 people, and the number of enterprises was about $1,770 .{ }^{[6]}$

\section{EXPERIENCE ACCUMULATED IN THE BUILDING OF CITY SUBSIDIARY-CENTERS IN JAPAN}

The building of Japan's city subsidiary-centers has achieved remarkable effects and enjoyed high reputation worldwide, so their experience accumulated in the process of construction can be drawn for references.

\section{A. Strengthen urban planning and law construction}

The planning and law should be executable. The inadequate provisions should be revised in a timely manner so the urban construction and transformation can have laws to abide by. Japan has attached great importance to the role of law in the urbanization process by constantly eliminating, modifying and improving the unrealistic and too futuristic laws and regulations. The urban construction and transformation of the old cities was carried out under the legal framework without subjecting to the will of any groups or individuals. The formulated planning and design program should be released to allow the public to monitor the implementation and prevent back case operation. ${ }^{[7]}$ For example, Ikebukuro strictly implemented related legal regulations; the design planning of Osaka Business Park was systemic in which the general building agreement and the local block agreements were coordinated with the integrated design planning to provision the land using proportion; the planning and construction of Shinjuku CBD was very detailed, full reflected the specified principles of "Shinjuku New urban center development agreement". A series targeted countermeasures was introduced to beautify the environment and remain the block landscape to keep the security of the area and the security management which prevented from the developer-led construction of the real estate, rather based on the reasonable planning of residential and commercial uses in proper implementation.

\section{B. Innovative design concept}

Take Osaka Business Park as an example, it adopted the philosophy of "placemaking" in which it has hidden away the bustling and lively commercial atmosphere in the back setting model, roof gardening and landscape square to bring the estimable quietness for citizens. As a result, it has gained a lot of popularity and has become the critically-acclaimed large commercial complex. Shinjuku has made the best use of the accumulation effect of transit hub to business and passenger flow as well as careful designing on transportation. The continuous improved integrated transport planning and detailed planning and sophisticated design to Shinjuku Station was one of the key factors for Shinjuku to become a sub-center; while making full use of agglomeration economies, the city also minimized the segmentation effect of transportation hub through the development and utilization of underground space and the circuit design of footbridges and pedestrians. ${ }^{[8]}$ Like Shinjuku, Makuhari also attached great importance to transportation planning and infrastructure construction, especially the perfection for express traffic. ${ }^{[9]}$

\section{Choice for the construction main body}

The main bodies of the sub-centers building in Japan are not consistent. Osaka Business Park took the civil construction as the main body. In 1970, "OBP development agreement committee" was sponsored by the landowners to implement the "OBP Plan." MM21 on the other hand, used public-private joint development form, in which the project was jointly developed by the government, corporations and Bank of Yokohama, different from the common practice of the international major cities which was to make up the huge development cost by high intensity real estate development to damage the development project market value. ${ }^{[10]}$ MM21 was not developed as a single pure commercial center, but rather highlighted the space and environment quality and cultural taste by creating harmonious urban comprehensive functions. Seen from the effects of the developed area, it is a forward-looking sub-center construction project in line with humanism and the principles of sustainable development. The development of Shinjuku sub-center also used a similar pattern which fully integrated the government positive plan and the market economy.

\section{Concern of the urban security issues}

The practice of Saitama New Urban Center is most systematic and most recommendable. The area has concentrated 14 bodies of 10 Japanese government ministries and is built whit a large venue Saitama Super Arena. In order to enhance the security disaster prevention functions of Saitama New Urban Center, large-scale temporary shelters and activity spots for disaster relief as well as disaster based hospitals were built. At present, Saitama New Urban Center disaster prevention facilities mainly include: national comprehensive government office building, Saitama Super Arena, Saitama Red Cross Hospital, and Omiya Police Department. At present, the disaster prevention functions of Saitama New Urban Center cover commanding, medical aid, material supply, concentrating and distributing of relief materials, collecting overseas relief materials, but not the functions of temporal assembling and camping for relief troops.

Other than the mentioned experiences, each sub-center has also carried out special practice based on their specific circumstances, such as listening to public opinion in the 
transformation planning process of old towns, paying attention to reasonable industrial layout, using high standards convention and exhibition features to stimulate the development of other urban functions, and so on. This also suggests that in building sub-centers, we need to follow the general rules and pay attention to our local conditions.

\section{SUMMARY}

The information described above focused on comprehensive and extensive only provides a general reference. Its intention is to ensure policymakers obtain macro-viewpoints, and also to provide a clue for the future collection of other information. To provide advisory services specifically for making policy to construct a city's deputy center, more detailed and profound information must be collected by long-term tracking. Not only information about current situation, characteristics and advantages but also the information about problems and its solution in the process of building a city sub center should be available.

\section{REFERENCES}

[1] Urban Households and Demographics 2016 Released by Toshima-Ku Website, Japan [EB/OL].[ July12, 2016] .

http://www.city.toshima.lg.jp/070/kuse/gaiyo/jinko/setaitojinko/1607121 048.html
[2] Statistical Density Map Released by Japan Statistics Bureau \& Statistics Center [EB/OL]. [July11, 2016].http://www.stat.go.jp/data/chiri/map. The density data of the Osaka Business Park in the following text all comes from this website.

[3] Japan Saitama City Website [EB/OL]. [July 12, 2016]. http://www.city.saitama.jp/Japanese Wikipedia“さいたま新都心”entry [EB/OL].[July 12,2016]. https://ja.wikipedia.org/wiki/\%E3\%81\%95\%E3\%81\%84\%E3\%81\%9F\% Е3\%81\%BE\% $\% 6 \% 96 \% \mathrm{~B} 0 \% \mathrm{E} 9 \% 83 \% \mathrm{BD} \% \mathrm{E} 5 \% \mathrm{BF} \% 83$

[4] The Population Statistics Data Released on Shinjuku Official Website, Japan [EB/OL]. [July 14, 2016].

https://www.city.shinjuku.lg.jp/kusei/index02_101.html. Other data about Shinjuku in the following text also comes from this website.

[5] Japanese Wikipedia "Makuhari New City" entry [EB/OL]. [July 15, 2016]. https://ja.wikipedia.org/wiki/Category:\%E5\%B9\%95\%E5\%BC\%B5\%E6 $\% 96 \% \mathrm{~B} 0 \% \mathrm{E} 9 \% 83 \% \mathrm{BD} \% \mathrm{E} 5 \% \mathrm{BF} \% 83$

[6] Japanese Wikipedia "Yokohama みなとみらい 21" entry[EB/OL].[July 15, 2016]. https://ja.Wikipedia.org/wiki/Yokohama みなとみらい 21

[7] Yu Weigang. Competition of Urban and Rural Areas and Protection of Remains in Space Fast Expansion Era - Case Study of Urbanization of Toshima-Ku, Tokyo, Japan [J]. Shanghai Urban Management, 2015, (3): 36-41.(In Chinese)

[8] Ma Haitao, Luo Kui, Sun Wei, Wang Yu. Experience and Inspiration of Building Sub-CBD: The Case of Shinjuku, Tokyo[J].World Regional Studies,2014, 23 (1): 103-110.(In Chinese)

[9] Shi Jian. Urban Design Guideline of Makuhari New City [N]. China Real Estate Business, July 18, 2005 (27).(In Chinese)

[10] Liu Chong. Building Tianjin International Port City with References to the Development Experience Yokohama of Japan [J].City, 2007 (4): 11-13.(In Chinese) 